Journal of Engineering and Applied Sciences 14 (Special Issue 3): 5974-5978, 2019

ISSN: 1816-949X

(C) Medwell Journals, 2019

\title{
Statistical Estimation View based on Mathematical Model for Predicting the Rotor Angle in Synchronous Motors
}

\author{
${ }^{1}$ Zainb Hassan Radhy and ${ }^{2}$ Hayder Al Ibraheemi \\ ${ }^{1}$ Faculty of Computer Science and Information Technology, University of Al-Qadisiyah, \\ Al Diwaniyah, Iraq \\ ${ }^{2}$ Faculty of Technical Engineering, Islamic University, Najaf, Iraq \\ Zainb.hassan@qu.edu.iq, alibraheemi20@gmail.com
}

\begin{abstract}
Statistical and mathematical analysis has currently a strong contribution in engineering applications. Synchronous motors, type Permanent Magnet (PM) currently stand in proceed position in many industrial applications. The accurate predicting for the angle of rotor at standstill condition plays an important role in safe motor running. This research presented a statistical view for this issue of rotor angle predicting by employing the obtained data from injection of electrical pulses in the motor coils. A mathematical model was built on MATLAB/Simulink environment to extract the accurate position with high resolution. The research results verified the statistical and mathematical analysis of the research problem.
\end{abstract}

Key words: Statistical estimation, electrical motor, rotor position, mathematical model, motor coils, MATLAB

\section{INTRODUCTION}

Since, the past two decades, the PM synchronous motors have started locating at a distinguished position in motor applications. As an instance, the pollution is currently a difficult challenge in modern life. Diesel engine vehicles have a significant responsibility for this hard situation. The promising features of PM synchronous motors which lead to this friendly transporting are summarized by high efficiency, small size, robust and non-noisy operation, identical torque, flexible controlling, etc. (Dost and Sourkounis, 2011; Assegaf et al., 2013; Fang et al., 2009; Jebai et al., 2016).

The statistical and mathematical analysis has witnessed a significant utilizing in field of engineering data interpretation and the corresponding result conclusions. For instance (Shi et al., 2013) employed the statistical analysis to establish a path planning of an aircraft to track the shortest path. Frosini et al. (2015) exploited the statistical processing to detect the fault in the bearing of induction machines. Whereas an optimum statistical estimator was obtained by Cai et al. (2015) to provide a high quality and low cost data.

This research addresses the difficulty of predicting rotor angle of PM synchronous motors through sensing the millivolt terminals voltages variations. These variations are exploited to create two address lines which are employed to access a 2Dlookup table whose cells contain the rotor position angles.

Theory: To run any PM synchronous motor, it is sufficient to excite only two of its three stator-coils at any instant of time, whilst the third is exploited as a voltage sensor (Iizuka et al., 1985). Such principle of testing was employed in this reseach where a short duration pulse was used as an excitation signal for any two coils. These two coils formed a two inductors series loop. Their voltages drops are observed via. the free terminal of the third coil. Figure 1a-c illustrate applying of short pulses at the gates of the switching elements (IGBTs) which respond by transferring to ON condition. The IGBT responses produce a voltage pulses between coil terminals. The amplitudes of these pulses equal the DC link voltage $V_{d c}$ and its duration equals to that of the applied pulse on the gates of the switching elements. When the pulses become at low states, the switching elements becomes at $\mathrm{OFF}$ conditions and the connection of coil terminals reverse via. the freewheel diodes.

Accordingly, six voltage measurements at the motor terminals during the active and passive periods of the three pulses, $\mathrm{V}_{\mathrm{NB} 1}, \mathrm{~V}_{\mathrm{NAF} 1}, \mathrm{~V}_{\mathrm{NC2} 2}, \mathrm{~V}_{\mathrm{NAF2} 2}, \mathrm{~V}_{\mathrm{NC3}}$ and $\mathrm{V}_{\mathrm{NBF3}}$ are obtained. These voltages are employed to create two

Corresponding Author: Zainb Hassan Radhy, Faculty of Computer Science and Information Technology, 

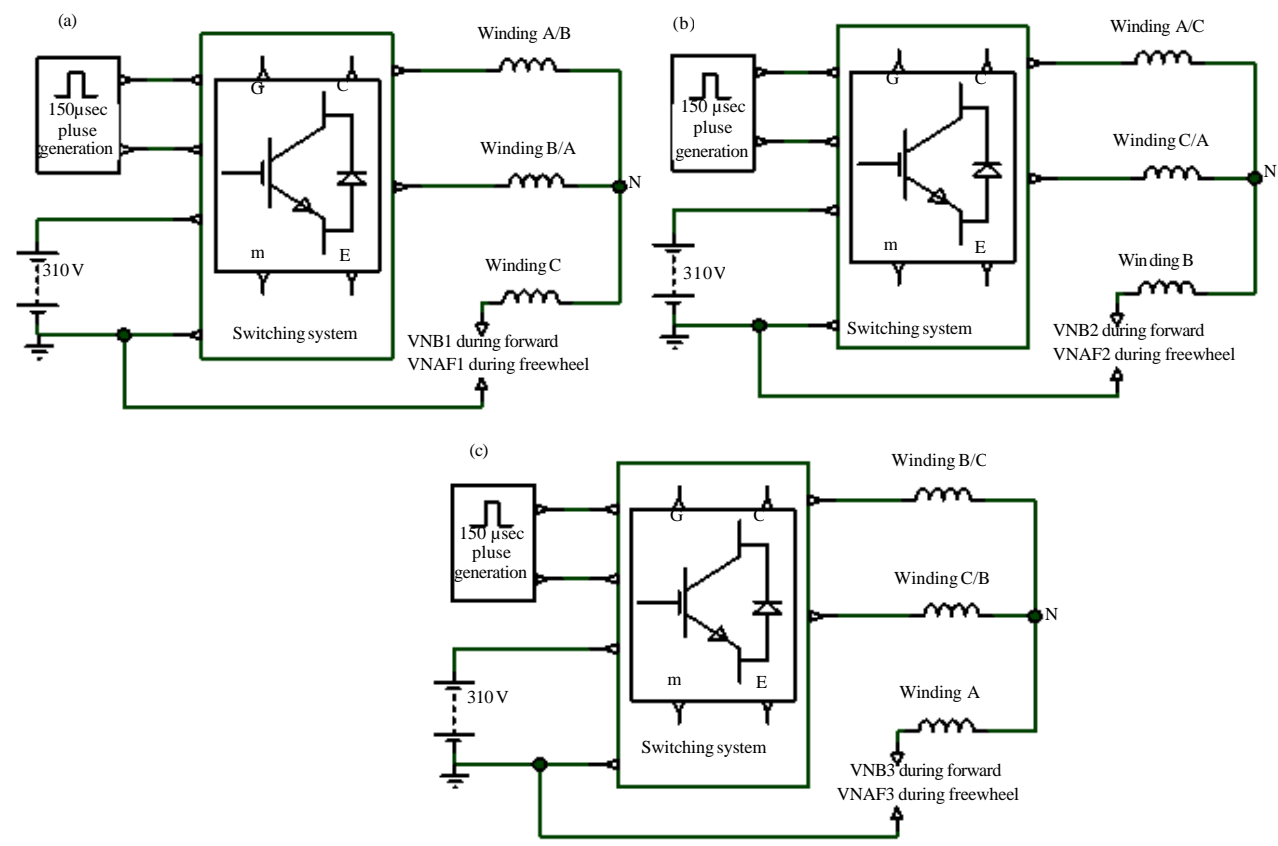

Fig. 1: a-c) Coil excitations and the freewheeling cycles
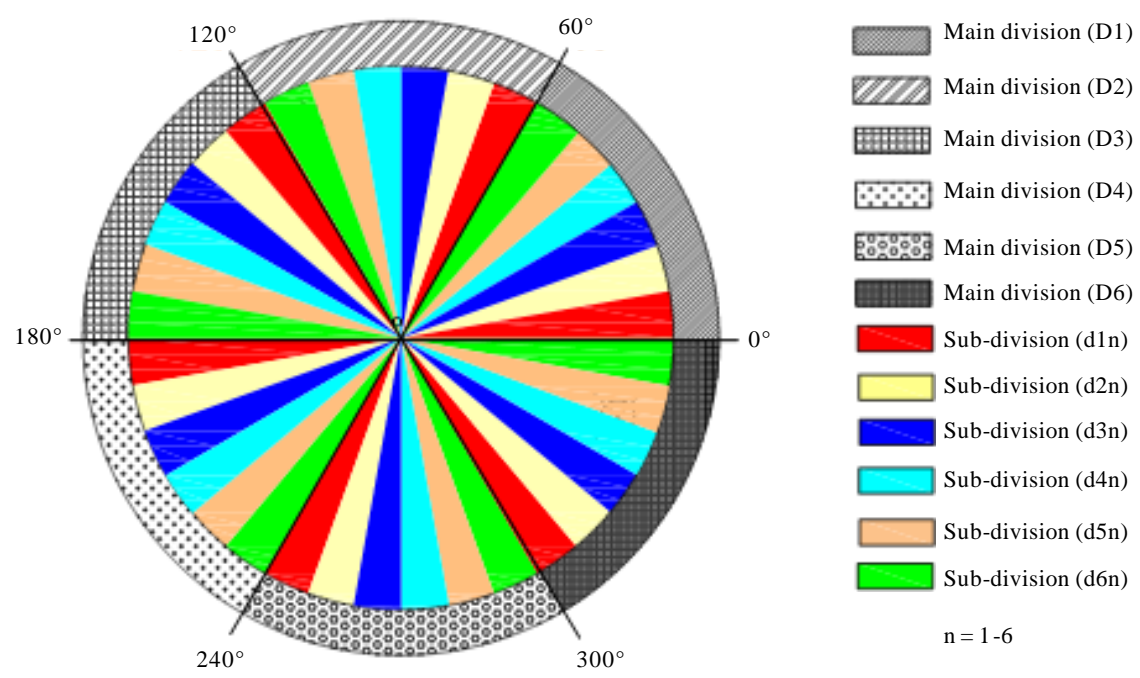

Fig. 2: Dividing the angles of rotor positions into main and sub divisions

address lines, $\mathrm{x}$-address line and $\mathrm{y}$-address line which are used to access the cells of 2D-lookup table where the angles of rotor positions are stored. Accordingly, for each two values of $\mathrm{x}$ and $\mathrm{y}$ dimensions, there will be a corresponding rotor angle which specify the rotor position at the moment of applying the pulses. The procedure of creating $\mathrm{x}$ and $\mathrm{y}$ dimensions can be illustrated below.

Creating the $\mathbf{x}$ dimension: The obtained results for the modelled PM synchronous motor which has three pole pairs show that the total rotor space is divided into six divisions $\left(D_{1}-D_{6}\right)$. Each division is further divided into six subdivisions. Figure 2 illustrates this division process. The division numbers are employed later to form the $\mathrm{x}$ dimension of the 2D-lookup table.

Creating the y-address line: Refer to Fig. 1a, let us consider the response $\mathrm{V}_{\mathrm{NB} 1}$ as an example for analysis of voltage responses, then it could be written in Eq. 1:

$$
\mathrm{V}_{\mathrm{NB1}}=\mathrm{V}_{\mathrm{dc}} \frac{\mathrm{Z}_{\mathrm{B}}}{\mathrm{Z}_{\mathrm{A}}+\mathrm{Z}_{\mathrm{B}}}
$$




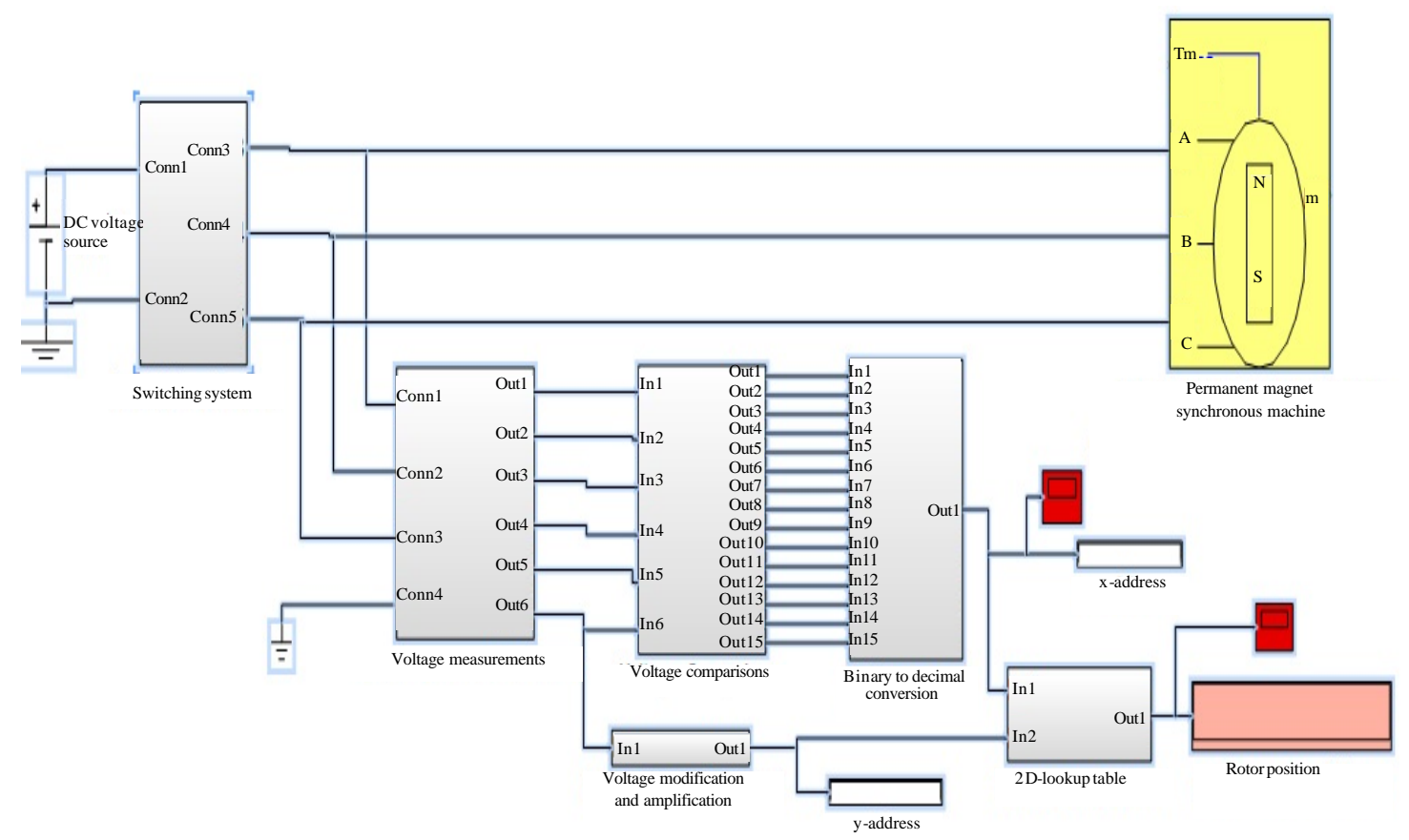

Fig. 3: MATLAB/Simulink implementation for rotor location prediction at standstill

Where:

$\mathrm{V}_{\mathrm{dc}}=$ The dc link pulse voltage which appears after triggering the IGBT by the first pulse

$\mathrm{Z}_{\mathrm{A}}, \mathrm{Z}_{\mathrm{B}}=$ Represent the impedances of coils $\mathrm{A}$ and $\mathrm{B}$, respectively

By complex form Eq. 1 is expressed as Eq. 2:

$$
V_{N B 1}=V_{d c} \frac{R_{B}+j \omega L_{B}}{\left(R_{A}+R_{B}\right)+j \omega\left(L_{A}+L_{B}\right)}
$$

where, ' $\omega$ ' is an angular frequency which is equivalent to the switching frequency of the inverter switching elements. This frequency is normally of very high value. Therefore, the resistive components in the numerator and denominator of Eq. 2 could be ignored comparing to the inductive components. Thereby, Eq. 2 could be rewritten as Eq. 3:

$$
\mathrm{V}_{\mathrm{NB} 1}=\mathrm{V}_{\mathrm{dc}} \frac{\mathrm{L}_{\mathrm{B}}}{\mathrm{L}_{\mathrm{A}}+\mathrm{L}_{\mathrm{B}}}
$$

This equation describes the response $V_{N B 1}$ as a function to values of coil inductances $\mathrm{L}_{\mathrm{A}}$ and $\mathrm{L}_{\mathrm{B}}$. As the inductances are functions to rotor position by the effect of rotor magnet salience. Indirectly, the measured voltage will be a function to rotor position and it will oscillate strongly as the rotor has a strong saliency. Thereby, the second dimension of the D-lookup table, $\mathrm{y}$-address line is created from such oscillation in voltage. Figure 3 illustrates the methods of creating this address line.

\section{MATERIALS AND METHODS}

Mathematical model: Let define a binary variable row vector $\mathrm{D}$ of Dimension $(\mathrm{n} \times 1)$ to denote the division vector where ' $n$ ' means to the expected number of divisions in rotor space. In this research $n=6$, so (Eq. 4):

$$
[\mathrm{D}]_{6,1}=\left[\mathrm{D}_{1} \mathrm{D}_{2} \mathrm{D}_{3} \mathrm{D}_{4} \mathrm{D}_{5} \mathrm{D}_{6}\right]^{\mathrm{T}}
$$

where, each element in the vector $\mathrm{D}$ is of binary representation, either 0 or 1 which is expressed in Eq. 5:

$$
D_{i}=\left\{\begin{array}{ll}
1, & \text { if } \mathrm{i}=\text { division reading } \\
0, & \text { otherwise }
\end{array} \text { where } \mathrm{i}=1,2, \ldots, 6(5)\right.
$$

Thereby, only one of $\mathrm{D}$ elements will be at $\operatorname{logic}$ ' 1 ' at any moment of time while all other will be at logic ' 0 ' because the rotor could not be at more than one division at a certain time. Likewise, a matrix $\mathrm{V}(\mathrm{m} \times \mathrm{n})$ of binary variables is assigned to expressed the voltage responses where $m$ denotes the number of responses in a certain division. In this research, $\mathrm{m}=60$ and illustrated in Eq. 6 : 


$$
[\mathrm{V}]_{60 \times 6}=\left[\mathrm{v}_{\mathrm{i}, \mathrm{j}}\right]=\left[\begin{array}{cccc}
\mathrm{v}_{1,1} & \mathrm{v}_{1,2} & \cdots & \mathrm{v}_{1,6} \\
\mathrm{v}_{2,1} & \mathrm{v}_{2,2} & \cdots & \mathrm{v}_{2,6} \\
\vdots & \vdots & \vdots & \vdots \\
\vdots & \vdots & \vdots & \vdots \\
\mathrm{v}_{60,1} & \mathrm{v}_{60,2} & \cdots & \mathrm{v}_{60,6}
\end{array}\right]
$$

where, $i$ denotes the division number and $j$ the score of voltage response within the ith division. Value of each element in the $\mathrm{V}$ matrix is defined by Eq. 7 :

$$
\mathrm{V}_{\mathrm{i}, \mathrm{j}}=\left\{\begin{array}{ll}
1, & \text { if } \mathrm{v}_{\mathrm{i}, \mathrm{j}}=\mathrm{v}_{\mathrm{r}} \pm 1 \% \mathrm{v}_{\mathrm{r}} \\
0, & \text { otherwise }
\end{array}, \mathrm{v}_{\mathrm{r}}\right. \text { is the voltage response }
$$

While, the possible rotor angles are given by the following matrix $\theta$. It gives the all locations distributed on the rows according to division number (Eq. 8):

$$
[\theta]_{\mathrm{n}, \mathrm{q}}=\left[\begin{array}{cccccc}
\theta_{1,1} & \theta_{1,2} & \cdots & \cdots & \cdots & \theta_{1,60} \\
\theta_{2,1} & \theta_{2,2} & \cdots & \cdots & \cdots & \theta_{2,60} \\
\vdots & \vdots & \vdots & \vdots & \vdots & \vdots \\
\vdots & \vdots & \vdots & \vdots & \vdots & \vdots \\
\theta_{6,1} & \theta_{6,2} & \cdots & \cdots & \cdots & \theta_{6,60}
\end{array}\right]
$$

Where:

' $\mathrm{n}$ ' $=$ Denotes the divsion number

' $\mathrm{q}$ ' $=$ The angles in the nth division

Then, define a matrix $M$ which equals to the multiplication of the three above matrices where (Eq. 9):

$$
\mathrm{M}_{\mathrm{k}, 1}=[\theta] \times[\mathrm{V}] \times[\mathrm{S}]
$$

Finally, the rotor location is obtained by:

$$
\text { Rotor postion }=\sum_{\mathrm{k}=1}^{60} \mathrm{M}_{1=\text { sector number }}
$$

MATLAB model: The simulated system for standstill SMPMSM rotor position estimation is given in Fig. 3. Specifications of the undertaken PM motor are given in Table 1.

Table 1: Specifications of motor under modelling

\begin{tabular}{ll} 
To. of phases & 3 \\
\hline Rotor type & Round \\
Stator phase resistance & $1 \mathrm{Ohm}$ \\
Stator inductance & $0.0055 \mathrm{mH}$ \\
Flux linkage & $0.285757(\mathrm{~V} . \mathrm{s})$ \\
Inertia, viscous damping & $0.000621417\left(\mathrm{~kg} \cdot \mathrm{m}^{2}\right), 0.000303448(\mathrm{Nms})$ \\
DC link voltage & $310 \mathrm{~V}$ \\
\hline
\end{tabular}

RESULTS AND DISCUSSION
The obtained results, according to applying the proposed mathematical model, showed that the model succeeded in estimating each angle of the rotor actual location. However, the results also indicated that the presented model failed in predicating the rotor angle at 21 locations out of 360 locations. Thereby, the total error rate is approximately equal to $5 \%$.

\section{CONCLUSION}

A novel mathematical method, of error $<1 \%$ has been presented in this study to predicate the rotor location of permanent magnet synchronous motor under standstill condition. It is concluded that the novelty has been validated by three promising achieved improvements which may maintain immune start up for the targeted motor. Firstly, the manner of simulation that allowed to exploit only the voltages terminals of the PM motor to obtain measurable voltage differences for each rotor location. Secondly, dispensing the magnet polarity detection allowed widely simplifying the technique of sensorless rotor location predictor. Finally, the achievement of $1^{\circ}$ resolution for rotor position estimation represented a significant progress comparing with other relevant techniques.

\section{REFERENCES}

Assegaf, A., A. Purwadi and Y. Haroen, 2013. Dynamic response analysis of permanent magnet synchronous motor drives for city electric car. Proceedings of the 2013 International Conference on Information Technology and Electrical Engineering (ICITEE), October 7-8, 2013, IEEE, Yogyakarta, Indonesia, ISBN:978-1-4799-0423-5, pp: 365-369.

Cai, Y., C. Daskalakis and C. Papadimitriou, 2015. Optimum statistical estimation with strategic data sources. JMLR. Workshop Conf. Proc., 40: 1-17.

Dost, P. and C. Sourkounis, 2011. Mechanical and electrical behaviour of an electric vehicles drive train due to the choice of the control-system. Proceedings of the 37th Annual International Conference on IEEE Industrial Electronics Society (IECON 2011), November 7-10, 2011, IEEE, Melbourne, Australia, ISBN:978-1 -61284-969-0, pp: 1426-1431.

Fang, S., B. Zhou and Y. Liu, 2009. Design and realization 
of dual redundancy PMSM electrical drive systems. Proceedings of the 2009 4th IEEE International Conference on Industrial Electronics and Applications, May 25-27, 2009, IEEE, Xi'an, China, ISBN:978-1-4244-2799-4, pp: 1985-1989.

Frosini, L., C. Harlisca and L. Szabo, 2015. Induction machine bearing fault detection by means of statistical processing of the stray flux measurement. IEEE. Trans. Ind. Electron., 62: 1846-1854.

Iizuka, K., H. Uzuhashi, M. Kano, T. Endo and K. Mohri, 1985. Microcomputer control for sensorless brushless motor. IEEE Trans. Ind. Appl., IA-21: 595-601.
Jebai, A.K., F. Malrait, P. Martin and P. Rouchon, 2016. Sensorless position estimation and control of permanent-magnet synchronous motors using a saturation model. Intl. J. Control, 89: 535-549.

Shi, T., H. Wang and F. Wang, 2013. Path planning of a four-rotor aircraft based on shortest path algorithm and statistical analysis. Proceedings of the 2013 10th International Conference on Fuzzy Systems and Knowledge Discovery (FSKD), July 23-25, 2013, IEEE, Shenyang, China, pp: 627-631. 